\title{
Complexos de nanofibras eletrofiadas e ácidos nucleicos: Uma revisão
}

\author{
Complexes of electrospun nanofibers and nucleic acids: A review \\ Complejos de nanofibras y ácidos nucleicos electrofilizados: Una revisión
}

Recebido: 12/04/2021 | Revisado: 17/04/2021 | Aceito: 18/04/2021 | Publicado: 30/04/2021

Edmo Henrique Martins Cavalcante

ORCID: https://orcid.org/0000-0003-0509-4475

Universidade Federal Rural de Pernambuco, Brasil E-mail: edmo-uni@outlook.com

Helinando Pequeno de Oliveira

ORCID: https://orcid.org/0000-0002-7565-5576

Universidade Federal do Vale do São Francisco, Brasil

E-mail: helinando.oliveira@univasf.edu.br

\begin{abstract}
Resumo
A interação entre células e nanoestruturas poliméricas vem sendo considerado um importante tema para a biotecnologia. As fibras eletrofiadas apresentam estruturas porosas na ordem de submícrons com características que mimetizam os componentes fibrilares da matriz extracelular natural, favorecendo a atuação local efetiva de sistemas bioativos. A complexação de ácidos nucleicos com essas fibras e sua utilização em terapias de recuperação funcional e regeneração tecidual podem ser alternativas ao transplante celular e aos sistemas de entrega de proteínas indutivas. $\mathrm{Na}$ customização do perfil de interação entre essas matrizes e o material genético, é relevante manter a disponibilidade de seus tipos moleculares em concentrações efetivas no microambiente, com maior expressão gênica e maior tempo de ação terapêutica. Ao se buscar equilíbrio entre eficiência de transfecção e a viabilidade celular, diferentes estratégias são seguidas, como a incorporação de polinucleotídeos em soluções poliméricas ou em emulsões antes do processo de eletrofiação, ou mesmo a funcionalização de nanofibras pela modificação de sua superfície. Diante disso, esta revisão tem por finalidade apresentar os diferentes métodos de produção de nanofibras eletrofiadas funcionalizadas com ácidos nucleicos e suas aplicações na área da saúde.
\end{abstract}

Palavras-chave: Nanofibras; Polinucleotídeos; Funcionalização.

\begin{abstract}
The interaction between cells and polymeric nanostructures has been considered an important topic for biotechnology. The electrospun fibers present porous structures in the order of submicron with characteristics that mimic the fibrillar components of the natural extracellular matrix, favoring the effective local action of bioactive systems. Complexation of nucleic acids with these fibers and their use in functional recovery and tissue regeneration therapies have been considered alternatives to cell transplantation and inductive protein delivery systems. In customizing the interaction profile between these matrices and the genetic material, it is relevant to maintain the availability of their molecular types in effective concentrations in the microenvironment, with greater gene expression and longer time for therapeutic action. The development of an adequate balance between transfection efficiency and cell viability, different strategies are followed, such as the incorporation of polynucleotides in polymeric solutions or emulsions before the electrospinning process, or even the functionalization of nanofibers by modifying their surface. Because of this, this review aims to present the different methods of producing electrophilic nanofibers functionalized with nucleic acids and their applications in the health area.
\end{abstract}

Keywords: Nanofibers; Polynucleotides; Functionalization.

\section{Resumen}

La interacción entre células y nanoestructuras poliméricas se ha considerado un tema importante para la biotecnología. Las fibras electrofilizadas tienen estructuras porosas del orden submicrónico con características que imitan a los componentes fibrilares de la matriz extracelular natural, favoreciendo la acción local efectiva de los sistemas bioactivos. La complejación de ácidos nucleicos con estas fibras y su uso en terapias de recuperación funcional y regeneración de tejidos pueden ser alternativas al trasplante celular y los sistemas de liberación de proteínas inductivas. Al personalizar el perfil de interacción entre estas matrices y el material genético, es relevante mantener la disponibilidad de sus tipos moleculares en concentraciones efectivas en el microambiente, con mayor expresión génica y mayor tiempo de acción terapéutica. Cuando se busca un equilibrio entre la eficiencia de transfección y la viabilidad celular, se siguen diferentes estrategias, como la incorporación de polinucleótidos en soluciones o emulsiones poliméricas antes del proceso de electrohilado, o incluso la funcionalización de nanofibras modificando su superficie. Por tanto, esta revisión tiene como objetivo presentar los diferentes métodos de producción de nanofibras electrofilizadas funcionalizadas con ácidos nucleicos y sus aplicaciones en el área de la salud.

Palabras clave: Nanofibras; Polinucleótidos; Funcionalización. 


\section{Introdução}

Nanofibras são materiais em escala submicrométrica e nanométrica que apresentam pequenos poros conectados às camadas de fibras aleatoriamente depositadas (Brown et al., 2011). Sua produção faz uso de técnicas aplicadas em larga escala como a fiação conjugada (Pike, 1999), fibrilação de película fundida (Perez et al., 2000) e a fiação por sopro em solução (Perez et al., 2000). Atendendo a diversas especificidades de síntese e as propriedades do material (viscoelasticidade, condutividade, temperatura de transição vítrea e de degradação térmica) em associação às características desejadas para as fibras (diâmetro, comprimento, conformação sólida ou tubular, alinhamento e regularidade das fibras), outras técnicas também são utilizadas: automontagem (Sun et al., 2017), molde estrutural (Tao \& Desai, 2007), separação de fases (J. F. Kim et al., 2016; Zheng et al., 2020), polimerização interfacial (El-Basaty et al., 2020), fiação por sopro em solução (Song et al., 2020) e a eletrofiação. Entre todos os métodos, a eletrofiação demonstra ser uma das mais simples e das mais reportadas na literatura (Deshawar et al., 2020). As fibras eletrofiadas apresentam características importantes que podem ser facilmente controlada, atendendo a requisitos de aplicações específicas em sensores, catálise e compósitos (Cheng et al., 2017; Villarreal-Gómez et al., 2016). As fibras eletrofiadas apresentam elevada razão entre área superficial e volume, poros altamente interconectados e com tamanhos controláveis pelas condições de preparação, possibilidades de funcionalização, morfologia de superfície ajustáveis e similaridade topográfica com a matriz extracelular (Li \& Xia, 2004; Sell et al., 2010).

As características das fibras eletrofiadas têm sido especialmente úteis em aplicações como filtração (Yin et al., 2020), catálise (Joshi et al., 2020; Liu, et al., 2020), curativos (Sandri et al., 2020), liberação de fármacos (Hou et al., 2020; Thakkar \& Misra, 2017), sistemas de conversão e armazenamento de energia (Chen et al., 2020; Yar et al., 2020), catálise (Yang et al., 2019), transportadores de enzimas (Chen et al., 2020), roupas de proteção UV (Zhu et al., 2015), sensores (Hui et al., 2017), semicondutores (Wu et al., 2017), microencapsulação (Akbar et al., 2018), adsorvedores (Barbosa et al., 2019) e etc. Na literatura, observa-se que a entrega de genes tem oferecido resultados promissores na introdução do agente terapêutico através de sua complexação com fibras eletrofiadas, oferecendo recuperação funcional ou regeneração em níveis celular e histológico (Malek-Khatabi et al., 2020). Em particular, na engenharia de tecidos, um dos mais importantes desafios é favorecer a adequada vascularização da região afetada visto que tecidos com espessura de poucos milímetros podem não favorecer a difusão de nutrientes e produtos do metabolismo (Phelps \& Garcia, 2009).

Um dos principais esforços se refere à utilização de fatores de estimulantes da angiogênese, como o fator de crescimento endotelial vascular (VEGF) e suas isoformas. Esses peptídeos são importantes na fase proliferativa e de maturação de processos de regeneração tecidual ao promoverem a estimulação de células endoteliais, a migração celular, além de mediarem a permeabilidade microvascular (Distler et al., 2002; Okonkwo \& DiPietro, 2017). Contudo, sua meia vida curta para aplicações in vivo e múltiplos sítios de ligação são incompatíveis com a manutenção de níveis terapêuticos (Rieux et al., 2011). Diante disso, esforços devem se voltar para entrega de fatores angiogênicos ao tecido isquêmico de maneira que atendam aos requisitos espacial e temporal de dosagem, evitando assim efeitos indesejados da administração sistêmica desses fatores (Phelps \& Garcia, 2009).

Shea et al., (1999) mencionam a abordagem baseada no transplante de células para matrizes poliméricas biodegradáveis, que orientam a formação de um novo tecido em determinada região anatômica antes de se degradarem. As limitações incluem a necessidade de isolamento e expansão de células in vitro, além do baixo índice de sobrevivência de muitos tipos de células após o transplante. Os autores citam também a utilização de proteínas indutivas como, por exemplo, as proteínas morfogenéticas ósseas (BMP) e fator de crescimento derivado de plaquetas (PDGF), cuja estabilidade pode ser reduzida pelos sistemas de entrega. 
Enquanto alguns estudos utilizam DNA puro para transferência local, outros utilizam carreadores coloidais de genes que empregam polímeros catiônicos para compactar DNA e melhorar a sua assimilação pela célula (Kim \& Yoo, 2010). A transferência de genes por transportadores não virais introduz alguns desafios que incluem a sua degradação no plasma, sua assimilação pelo sistema mononuclear fagocitário e degradação lisossomal (Pouton \& Seymour, 2001). Além disso, foi observado por Shea et al., (1999) que a injeção de plasmídeo não afeta significativamente a formação de tecido devido aos baixos níveis de transferência gênica e expressão celular. Eles concluíram que a utilização de matrizes de poli(ácido lático-coácido glicólico) (PLGA) com DNA plasmídeo (pDNA) permite sua liberação controlada in vivo, levando à produção terapêutica de proteínas indutivas, o que melhora o desenvolvimento tecidual.

A literatura aborda também a utilização de nanofibras como alternativa aos tratamentos oncológicos convencionais, que são administrados de forma sistêmica. Uma estratégia é sua funcionalização com RNAi para inibir a tradução do mRNA, suprimindo localmente a expressão oncogênica ou induzindo a apoptose celular (Monaghan \& Pandit, 2011). Experimentos com esse objetivo foram conduzidos por Achille et al. (2012), que produziram nanofibras de policaprolactona (PCL) com plasmídeos codificadores de pequenos grampos de RNA (short hairpin RNA, shRNA). Esses grampos foram capazes de silenciar o gene-alvo Cdk2, reduzindo a proliferação e viabilidade de células tumorais MCF-7 de neoplasia de mama. A respeito da via de interferência por RNAi para controle de expressão gênica, o principal desafio é manter a disponibilidade de seus tipos moleculares nas aplicações de longo prazo (Raemdonck et al., 2008).

Nos experimentos que envolvem transfecção de genes, é importante considerar a sua liberação controlada com o objetivo de atingir concentrações efetivas no microambiente que circunda a célula. Nie et al. (2009) observaram que baixas concentrações de DNA resultam em menor eficiência de transfecção. Isso também pode ser atribuído à abundância de complexos de genes após sua rápida liberação pela matriz, podendo perder sua funcionalidade quando não são incorporados ao genoma celular no devido tempo (Nie \& Wang, 2007).

Diante disso, a incorporação de DNA, fatores de crescimento e enzimas conjugadas a fibras tem sido utilizada para preservar sua bioatividade e funcionalidade. Esses nanomateriais têm sido promissores na medicina regenerativa por serem biodegradáveis e biocompatíveis, apresentarem interconectividade controlada com estrutura porosa para cultura celular e possuírem propriedades mecânicas que podem mimetizar os componentes fibrilares da matriz extracelular natural (Roether et al., 2018). As nanofibras melhoram a adsorção de moléculas de adesão celular, induzem interações entre a célula e a matriz extracelular, suportam a diferenciação de células estaminais e ativam vias de sinalização celular (Li; Shanti \& Tuan, 2007).

Para isso, as matrizes eletrofiadas incluem topografias da ordem de centenas de nanometros que permitem a utilização de nanofibras como substrato para cultura celular com dimensões comparáveis às da matriz celular nativa, tendo atuação local efetiva de sinais bioativos (Baek et al., 2020; Chew et al., 2006). Dvir et al. (2011), contudo, salientam que os diâmetros das fibras eletrofiadas estão usualmente no limite superior da faixa de 50 a $500 \mathrm{~nm}$ observada nessa matriz. Em geral, para porosidade de $20 \%$, a largura média dos poros é o dobro do diâmetro médio das fibras; para $80 \%$, essa média é 20 vezes maior (Greiner \& Wendorff, 2007). Assim, biomoléculas, cuja dimensão é da ordem de uns poucos nanômetros, podem facilmente se difundir no meio.

Por outro lado, nanofibras de peptídeos produzidas por automontagem possuem diâmetros da ordem de $10 \mathrm{~nm}$ formando poros que variam de 10 a $200 \mathrm{~nm}$, o que permite envolver as células de maneira similar à matriz extracelular natural. Esses sistemas de cultura tem a vantagem de incluírem estruturas secundárias funcionais que promovem aderência, diferenciação e maturação (Gelain et al., 2006). 


\section{Metodologia}

Esta revisão tem caráter analítico, qualitativo e integrativo, uma vez que que busca reunir o conhecimento referente ao estado da arte em encapsulação de ácidos nucléicos por fibras poliméricas eletrofiadas. Com a quantidade cada vez maior de procedimentos de encapsulação de material genético em complexos poliméricos, resolvemos estender este olhar integrativo sobre diferentes metodologias que contemplam deste procedimento. A coleta de dados foi realizada no período de janeiro/2020 a dezembro/2020 utilizando-se do Web of Science e Scientific Eletronic Library Online (SCIELO).

\section{Resultados e Discussão}

A eletrofiação é uma técnica eletrohidrodinâmica que utiliza forças eletrostáticas para produção de fibras com diâmetros na ordem de submícrons a partir de um fluxo de fluido carregado eletricamente (Huang et al., 2014). Em geral, a eletrofiação é conduzida a partir de uma solução polimérica dopada com aditivos de interesse.

A técnica de eletrofiação de solução polimérica inclui o processamento de polímeros termicamente instáveis e é feita mediante evaporação de solventes orgânicos (Persano et al., 2013; Wang \& Nakane, 2020). Esse processo pode ocorrer em banho de coagulação contendo um solvente miscível no solvente do polímero, o que auxilia na sua solidificação. Uma variante desse processo é o eletrofiação em imersão desenvolvido por Shepherd et al. (2017) e Divvela et al. (2018), que produziram fibras em nanoescala pela coagulação do polímero ejetado em um meio dielétrico líquido composto por clorofórmio e óleo mineral (Košt’áková et al., 2014). A eletrofiação úmida costuma ser mais lenta que a técnica convencional, que requer a evaporação do solvente a partir do filamento (Brown et al., 2016).

A técnica de eletrofiação por fusão (MES), por outro lado, é capaz de produzir fibras a partir da extrusão de uma dispersão sólida de polímeros (Balogh et al., 2015). Na biologia celular são comumente utilizados polímeros biodegradáveis, como PCL e poli(L-lactídeo) (PLA). Além desses polímeros orgânicos sintéticos, biopolímeros naturais como DNA, fibroína de seda, fibrinogênio bovino e humano, dextranos, colágeno ou mesmo vírus tem sido utilizados com sucesso na eletrofiação (Li \& Xia, 2004).

A configuração convencional para o sistema de eletrofiação consiste em três componentes principais: uma fonte de alta tensão, uma agulha e coletor eletricamente aterrado. Na eletrofiação coaxial, em particular, soluções poliméricas diferentes são ejetadas de forma independente através de capilares concêntricos, permitindo a formação de um compósito com morfologia secundária do tipo núcleo-casca (Li et al., 2020). O coletor, por sua vez, pode assumir diferentes configurações: a de uma superfície plana ou de um eixo rotativo, dispostos verticalmente ou horizontalmente (Chen et al., 2017).

Na saída do capilar, o campo elétrico resulta em uma força repulsiva no fluido, afilando-o na forma de Cone de Taylor, em um ângulo de 49,3 (Taylor, 1969). Quando a tensão superficial é vencida, o fluido é impulsionado em direção ao coletor sobre o qual ocorre deposição de malha de não-tecido. Isso se deve às instabilidades adquiridas durante o alongamento do fluido e a seu movimento de instabilidade aerodinâmica conduzido por forças fletoras não axissimétricas (Deshawar \& Chokshi, 2018). A literatura apresenta alguns motivos que explicariam essa instabilidade, como resultado das interações de repulsão no jato (Yarin et al., 2001), do aumento da densidade de carga durante o alongamento do jato, aumentando a repulsão radial o que pode levar à separação do jato (Doshi \& Reneker, 1995) e da instabilidade aerodinâmica (Montinaro et al., 2015).

A fibra resultante possui diâmetro que varia de $100 \mathrm{~nm}$ a dezenas de micrometros, além de elevada área superficial por unidade de massa, da ordem de $10^{3} \mathrm{~m}^{2} \cdot \mathrm{g}^{-1}$ naquelas fibras com menor diâmetro (Chronakis, 2015). Um maior controle sobre essa deposição é operar na região estável próximo ao capilar, reduzindo sua distância em relação ao coletor, o que pode limitar a capacidade de remoção de solvente por evaporação durante a eletrofiação convencional (Han et al., 2007). Contudo, é possível imergir a fibra em banho ultrassônico seguida de secagem para remoção do solvente residual (Nabzdyk et al., 2014). 
Diante disso, é importante considerar a técnica eletrofiação úmida quando o acúmulo e a toxicidade do solvente são um problema na eletrofiação convencional. A temperatura de transição vítrea e de degradação térmica devem ser observadas nesse processo, não sendo indicados polímeros termofixos e termicamente instáveis além de proteínas (Xue et al., 2019). Durante o processo, pode ocorrer degradação térmica induzida por temperaturas elevadas durante a fusão do material (Balogh et al., 2014; Xue et al., 2017).

Devido à menor condutividade elétrica e maior viscosidade do polímero fundido comparadas à solução polimérica, o diâmetro das fibras produzidas por eletrofiação úmida são tipicamente maiores (Liu et al., 2020). Isso se deve à necessidade de forças perturbadoras crescentes para superar a tensão superficial do polímero fundido, que pode ser extraído a uma distância maior, mantendo sua trajetória linear como resultado do aumento da região de estabilidade entre o capilar e o coletor (Li et al., 2020; Zhou et al. 2006). Por esse motivo, a técnica tem sido amplamente aplicada na produção de malhas de fibras ordenadas.

Durante o processo de eletrofiação, fatores extrínsecos e intrínsecos modulam a morfologia estrutural das nanofibras, devendo ser considerados na customização do perfil de interação com ácidos nucleicos. Além disso, a cinética de liberação dessas moléculas dependem invariavelmente da morfologia (Zandi et al., 2020). Os fatores extrínsecos envolvem umidade e temperatura do ambiente e os intrínsecos estão relacionados ao processo e à solução polimérica, de modo que a abundância de estruturas fibrosas é explicada pela contribuição relativa desses parâmetros bem como de sua dependência em relação à natureza do polímero utilizado (Doshi \& Reneker, 1995; Li \& Tuan, 2009).

\subsection{Importância dos fatores de produção de fibras eletrofiadas}

A tensão elétrica e a taxa de injeção da solução são menos efetivas em controlar a morfologia das fibras quando comparadas aos parâmetros de solução (Chronakis, 2015). A tensão aplicada apresenta menor efeito sobre a formação de gotas e diâmetro da fibra do que a concentração da solução e o solvente utilizado (Jacobs et al., 2010). Contudo, a correlação entre espessura da fibra e a tensão utilizada é ambígua. Em geral, a intensidade do campo elétrico em uma pequena distância entre a ponta do capilar e o substrato permite reduzir substancialmente a tensão aplicada (Huang et al., 2013). Fibras de maior espessura, em geral, são resultado também de maiores taxas de infusão, com as quais maior volume de solução é levado para a ponta do capilar (Ziabari et al., 2010).

A elasticidade do fluido, determinada pela massa molecular do polímero, e sua concentração são fatores a serem considerados na redução de imperfeições na rede resultante (Huan et al., 2015; Yu et al., 2006). Uma dispersão deve apresentar um polímero de massa molecular elevada o suficiente para que ocorra o emaranhamento de cadeia (Luo et al., 2012). Quando não há atração coesiva suficiente para estabilizar o jato carregado, a solução é aspergida em direção ao coletor ou pode ainda formar fibras com defeitos do tipo pérolas, como resultado de instabilidades observadas também em processos como a atomização eletrostática (Gañán-Calvo, 1997).

Como a maioria das fibras eletrofiadas são produzidas a partir de soluções poliméricas, o diâmetro das fibras pode variar com a sua concentração. Em geral, maiores concentrações do polímero normalmente resultam em fibras de maior diâmetro; quando muito elevadas, produzem grande resistência à formação do jato (Kara et al., 2020). Liu e Reneker (2019) salientam que mudanças no diâmetro do jato inicial e a inclinação observada na transição da gota para jato podem invalidar essa correlação. As interações entre polímero e solvente são favorecidas pela elevada solubilidade, o que permite com que as cadeias se expandam e maximizem essas interações. O uso de solventes de menor solubilidade aumenta a interação entre essas cadeias (Luo et al., 2012). 


\subsection{Interações com ácidos nucleicos}

Interações de matrizes eletrofiadas com polinucleotídeos podem ser feitas por diferentes técnicas que incluem a encapsulação dessas moléculas a partir da eletrofiação de emulsões, soluções ou suspensões, podendo constituir fases concêntricas, como na eletrofiação coaxial. As fibras também podem ser funcionalizadas após a eletrofiação. Esses processos envolvem a seleção de materiais e condições de processamento para preservação da bioatividade dos agentes terapêuticos (Zamani et al., 2013).

\subsubsection{Encapsulação}

A encapsulação é o método mais simples no qual o ácido nucleico é disperso em solução polimérica para subsequente fabricação de uma matriz híbrida com uma fase. A interação entre moléculas influencia na eficiência de encapsulação, a partir de sua distribuição no interior da fibra, bem como sua cinética de liberação. Assim, é importante considerar a combinação de polímeros hidrofílicos e hidrofóbicos para melhorar a encapsulação de polinucleotídeos e controlar sua liberação (Cao et al., 2010). A utilização de polímero hidrofílico como o polietilenoimina (PEI), por exemplo, acelera a liberação de pDNA ao passo em que a encapsulação de poliplexos de oligonucleotídeos no interior da fibra pode retardá-la após o pico inicial de liberação (Yang et al., 2011).

A Tabela 1 apresenta aplicações para a encapsulação de ácidos nucléicos previamente incorporados à solução polimérica. Percebe-se que o método predominantemente utilizado é a eletrofiação convencional com capilar simples ou coaxial. A utilização desses capilares resulta em diferentes cinéticas de liberação dos oligonucleotídeos.

Em geral, biomoléculas tendem a se acumular na superfície da fibra durante a eletrofiação, sendo inicialmente liberadas em grandes quantidades, o que vem a afetar a sua biodisponibilidade no período de tratamento (Liu et al., 2020). A liberação pode ser controlada por meio da degradação do componente biodegradável da matriz. Dessa forma, a incorporação de polímeros como polietilenoglicol (PEG) pode aumentar a disponibilidade de oligonucleotídeos ao sofrerem dissolução em contato com o meio, o que aumenta a área de contato da matriz eletrofiada e acelera sua degradação (Yang et al., 2012).

Por outro lado, a eficiência de transfecção de material genético é melhorada quando utilizadas nanopartículas, técnicas de eletrofiação coaxial ou modificação de superfície (Kim \& Yoo, 2010; Liao et al., 2009; Nie \& Wang, 2007). A utilização de polilactídeo para formação de estruturas micelares com pDNA condensado foi eficaz em proteger o material genético durante a eletrofiação e permitir sua transfecção (Liang et al., 2005). A configuração núcleo-casca, por sua vez, tem resultado em melhores perfis de liberação, além de melhor biocompatibilidade e propriedades mecânicas em aplicações da engenharia de tecidos quando comparadas às fibras produzidas por capilar simples (Nagiah et al., 2015). 
Tabela 1: Encapsulação ácidos nucleicos pelo método de eletrofiação.

\begin{tabular}{|c|c|c|c|c|c|}
\hline Polímeros $^{1}$ & Solventes $^{2}$ & Ácido nucleico ${ }^{3}$ & Aplicação & Capilar & Referência \\
\hline- & Etanol e água & Na-DNA & Entrega gênica & Simples & (Fang \& Reneker, 1997) \\
\hline PLGA, PLA-PEG & DMF & pDNA & Entrega gênica & Simples & (Luu et al., 2003) \\
\hline PLGA, LEL & DMF & pDNA-LEL & Entrega gênica & Simples & (Liang et al., 2005) \\
\hline PEO & Água & Na-DNA & - & Simples & (Liu et al., 2007) \\
\hline $\begin{array}{l}\text { PCL, PEI-HA } \\
\text { PEG }\end{array}$ & $\begin{array}{l}\text { Metanol e } \\
\text { clorofórmio, } \\
\mathrm{NaCl}_{(\mathrm{aq})}\end{array}$ & pDNA & $\begin{array}{l}\text { Engenharia de } \\
\text { tecidos }\end{array}$ & Coaxial & (Saraf et al., 2010) \\
\hline PCL, PEG & TFE & siRNA & Entrega gênica & Simples & (Cao et al., 2010) \\
\hline PCLEEP & TFE & $\begin{array}{l}\text { siRNA } \\
\text { siRNA-TKO }\end{array}$ & Entrega gênica & Simples & (Rujitanaroj et al., 2011) \\
\hline PCL & DMF e THF & pDNA & $\begin{array}{l}\text { Silenciamento de } \\
\text { gene }\end{array}$ & Simples & (Achille et al., 2012) \\
\hline $\begin{array}{l}\text { PLGA } \\
\text { PEI }\end{array}$ & $\begin{array}{l}\text { Casca: HFIP } \\
\text { Núcleo: água }\end{array}$ & pDNA & $\begin{array}{l}\text { Engenharia de } \\
\text { tecidos }\end{array}$ & Coaxial & (Xie et al., 2016) \\
\hline
\end{tabular}

1. PLGA (poli(ácido lático-co-ácido glicólico)), PLA-PEG (poli(D,L-lactídeo)-poli(etileno glicol)), LEL (copolímero tribloco de ácido polilático-b-polietilenoglicol-b-ácido polilático), PEO (poli(óxido de etileno)), PCL (policaprolactona), PEI-HA (polietilenimina-ácido hialurônico), PCLEEP (caprolactona-co-fosfato de etileno etílico).

2. DMF (N,N-dimetilformamida), TFE (2,2,2-trifluoroetanol), THF (tetraidrofurano), HFIP (1,1,1,3,3,3 hexafluoro2-propanol).

3. pDNA (DNA plasmídeo), siRNA (RNA de interferência curto), siRNA-TKO (RNA de interferência curto com agente de transfecção TKO).

Fonte: Os autores (2021).

O primeiro estudo sobre eletrofiação de polinucleotídeos foi desenvolvido por Fang e Reneker (1997), que utilizaram Na-DNA de timo de bezerro como polímero em soluções aquosas contendo diferentes concentrações de etanol. Outro estudo similar, utilizando DNA de testículo de salmão, foi conduzido por Takahashi et al. (2005).

A primeira entrega de genes utilizando encapsulação de DNA por eletrofiação foi reportada por Luu et al. (2003). Eles conseguiram controlar a liberação do pDNA pela mudança na composição polimérica da fibra de PLGA com diferentes concentrações do copolímero em bloco PLA-PEG. Eles observaram que a liberação do DNA é mais lenta e menos eficiente à medida que a relação superfície-volume diminui. A modulação da cinética de liberação bem como as propriedades de transfecção gênica foram demonstrados por Saraf et al. (2010) por meio dos parâmetros de processamento das matrizes estudados.

Nanofibras de PLGA também foram produzidas por Liang et al. (2005) que utilizaram micelas de pDNA inicialmente dispersos em N,N-dimetilformamida (DMT). O pDNA condensado foi encapsulado em copolímero tribloco de ácido 
polilático-b-polietilenoglicol-b-ácido polilático (LEL). Os autores observaram que sua presença protegeu o núcleo de degradação mantendo sua bioatividade após a eletrofiação sem, no entanto, ter efeito significativo sobre morfologia das matrizes. A eficiência de transfecção foi maior quando as células foram colocadas nas fibras ao invés do meio de cultura celular, o que os autores atribuíram à maior concentração local de DNA e à maior adesão das células às fibras. Quanto ao solvente, é sabido que essas moléculas poderiam permanecer intactas em DMF, sendo o tamanho do DNA um dos principais parâmetros na determinação do seu grau de desnaturação (Ke et al., 2010).

Outra estratégia de proteção do agente bioativo é sua encapsulação no núcleo da fibra através da eletrofiação coaxial, tendo a casca como uma barreira física (Chou et al., 2015). Saraf et al. (2010), por exemplo, avaliaram diversos parâmetros de processamento em experimentos fatoriais fracionados na qual produziram fibras por eletrofiação coaxial com casca de PEI-HA e PCL e com seu núcleo constituído de PEG e pDNA.

$\mathrm{O}$ pDNA em sua forma condensada, como resultado da presença de $\mathrm{NaCl}$ e PEG de maior peso molecular, pode potencialmente sofrer menos retenção no interior da fibra coaxial, aumentando sua liberação e subsequente transfecção. A complexação do pDNA com o r-PEI-HA, por outro lado, influencia na cinética de liberação pelo diferencial de condensação do material genético no interior da fibra coaxial. O método de eletrofiação coaxial minimiza a interação do plasmídeo com solventes orgânicos, além de permitir a integração do pDNA sem a necessidade de processamento prévio para diminuir sua bioatividade (Saraf et al., 2010).

Neste ponto, é importante ressaltar que o DNA apresenta elevada densidade de carga e sua estrutura helicoidal garante sua rigidez termodinâmica. Em solução com baixa concentração de $\mathrm{NaCl}$, a molécula de DNA apresenta uma conformação aleatória, menos flexível que moléculas policatiônicas. Nessas condições, a viscosidade intrínseca do DNA, que é proporcional ao seu volume molecular, é bastante elevada. Em $0,1 \mathrm{M}$ de NaCl, por exemplo, a viscosidade intrínseca do DNA é cerca de 170 vezes maior que a do PAA; a mesma condição é observada na presença de outros policátions (Kasyanenko et al., 2007).

Em contraste com os experimentos que utilizam pDNA para expressão de proteínas específicas, a entrega de siRNA resulta da repressão uma expressão proteica específica. Cao et al. (2010), por exemplo, produziram fibras eletrofiadas de PCL com diferentes concentrações de PEG aplicado no controle da taxa de liberação de siRNA. A matriz serviu de reservatório de siRNA com ação terapêutica de longo prazo, com melhor silenciamento gênico como resultado da ausência de mudanças significativas nesse efeito ao longo do tempo, sugerindo que o processo de encapsulação pode oferecer melhor proteção à molécula em condições fisiológicas. Rujitanaroj et al. (2011), por sua vez, utilizaram fibras eletrofiadas de um copolímero de caprolactona e etil etileno fosfato (PCLEEP). O siRNA permaneceu encapsulado e em liberação contínua por 28 dias, o mesmo tempo observado por Cao et al. (2010).

No estudo conduzido por Achille et al. (2012) o pDNA incorporado às fibras de PCL permaneceram bioativas, com capacidade de realizar transfecção para células MCF-7, transcrição e tradução, além do silenciamento do gene-alvo, com redução de 50\% dos níveis de Cdk2 mRNA. Eles observaram ainda que uma supressão de $40 \%$ no nível de proliferação celular, o que é comparável à redução de 37\% atribuída a transfecção direta com plasmídeo codificador de Cdk2 shRNA.

Os experimentos mostraram a viabilidade na utilização de nanofibras no fornecimento de sinais topográficos e bioquímicos sinérgicos para regulação do comportamento celular por meio da liberação controlada de RNA de interferência. Essa molécula pode atuar em nível transcricional, alterando a formação de heterocromatina, e em nível pós-transcricional, inibindo a tradução de mRNA alvo ou então controlando sua através do complexo de silenciamento (Monaghan \& Pandit, 2011). 


\subsubsection{Emulsão}

A Tabela 2 apresenta aplicações da encapsulação de ácidos nucléicos envolvendo a formação de emulsões homogêneas a partir das fases orgânica e aquosa. Nessa abordagem, o oligonucleotídeo é emulsificado em uma solução polimérica antes do processo de eletrofiação.

No entanto, as forças de cisalhamento e interfaciais que podem atuar entre duas fases podem danificar a macromolécula. Por isso, He et al. (2012) e Yang et al. (2011) recomendam condensar o DNA para evitar sua desnaturação durante o processo de eletrofiação. Sua interação com grupos amina de polímeros catiônicos pode reduzir o tamanho do ácido nucleico da ordem de micrômetros para ordem de centenas de nanômetros (Smedt et al., 2000).

Tabela 2: Encapsulação de DNA pelo método de eletrofiação por emulsão.

\begin{tabular}{llllll}
\hline Polímeros $^{1}$ & Solventes $^{2}$ & Ácido nucleico & Aplicação & Capilar & Referência \\
\hline PLGA/HAp & DCM e água & DNA/quitosana & Entrega gênica & Simples & (Nie \& Wang, 2007) \\
PLGA & DCM e água & DNA/quitosana & Engenharia de tecidos & Simples & (Nie et al., 2009) \\
PELA e PEG & Clorofórmio e água & pDNA & Entrega gênica & Coaxial & (Yang et al., 2011) \\
& & pDNA/PEI & & & \\
PELA e PEG & Clorofórmio e PBS & pDNA/PEI & Engenharia de tecidos & Coaxial & (Yang et al., 2012) \\
PELA e PEG & Água e clorofórmio & pDNA/PEI & Entrega gênica & Coaxial & (He et al., 2012) \\
\hline
\end{tabular}

1. PLGA/HAp (poli(ácido lático-co-ácido glicólico)/hidroxiapatita), PLGA ((poli(ácido lático-co-ácido glicólico)), PEI (polietilenimina), PELA (poli(etileno glicol)-poli(D,L-lactídeo)), PEG (polietilenoglicol).

2. DCM (diclorometano), PBS (tampão fosfato-salino).

Fonte: Os autores (2021).

Nie e Wang (2009) encapsularam complexos de pDNA e quitosana em compósitos de PLGA com diferentes concentrações de HAp. Nos tratamentos em que nanopartículas de pDNA/quitosana foram incorporadas às nanofibras, houve significativo aumento nas concentrações de sérum de plasmídeo após quatro semanas, havendo expressão duradoura. Nas fibras que sofreram modificação de superfície com as nanopartículas e com DNA puro, esse aumento ocorreu nas duas primeiras semanas. Yang et al. (2011), por sua vez, produziram emulsões que foram eletrofiadas em fibras com núcleo constituído de pDNA ou poliplexos de pDNA-PEI. A adição de PEG na matriz teve efeito significativo no controle do perfil de liberação desses poliplexos entre 6 e 25 dias, aumentando a eficiência de transfecção e a viabilidade celular. Testes in vivo em ratos diabéticos apresentaram liberação gradual de pDNA seguida da expressão significativa de fatores de crescimento, o que resultou na rápida recuperação de ferimentos, com completa reepitelização e regeneração dos apêndices da pele (Yang et al., 2012).

A importância da utilização desses poliplexos de pDNA encapsulados na expressão genética foi observada por He et al. (2012). Eles observaram a liberação continuada de pDNA a partir das fibras eletrofiadas, além da transfecção celular e expressão proteica. Em condições in vivo, eles observaram uma depleção mais intensa dos policátions, o que provocou uma condensação parcial do plasmídeo liberado. 


\subsubsection{Modificação superficial}

Na modificação de superfície, polinucleotídeos são ligados ou conjugados à superfície das fibras para acrescentar-lhe biofuncionalidade, não sendo expostos ao processo de eletrofiação. Como se pode observar na Tabela 3, a funcionalização pode ocorrer pela adsorção direta dos polinucleotídeos (Nie \& Wang, 2007) ou alternadamente das espécies multivalentes complementares (Sakai et al., 2009), pela incorporação de pDNA previamente encapsulado com nanopartículas (Nie \& Wang, 2007) ou ainda pela utilização de ligantes cliváveis para bioconjugação (Kim \& Yoo, 2010, 2013).

Tabela 3: Nanofibras modificadas com ácidos nucleicos na superfície.

\begin{tabular}{|c|c|c|c|c|c|c|}
\hline Polímeros ${ }^{1}$ & Solventes $^{2}$ & Incorporação & Ácido nucleico ${ }^{3}$ & Aplicação & Capilar & Referência \\
\hline \multirow[t]{2}{*}{ PLGA } & DCM e água & Adsorção física & DNA & Entrega gênica & Simples & (Nie \& Wang, 2007) \\
\hline & & & DNA/quitosana & & & \\
\hline \multirow[t]{2}{*}{ PLGA } & DCM e água & Adsorção física & DNA & Engenharia de & Simples & (Nie et al., 2009) \\
\hline & & & DNA/quitosana & tecidos & & \\
\hline PLLA & Clorofórmio & Camada a camada & DNA/PEI & Entrega gênica & Simples & (Sakai et al., 2009) \\
\hline PCL-PEG & $\begin{array}{l}\text { Metanol e } \\
\text { clorofórmio }\end{array}$ & Bioconjugação & pDNA & Entrega gênica & Simples & (Kim \& Yoo, 2010) \\
\hline PCL, PEI e & Clorofórmio, DMF & Adsorção física & pDNA & Entrega gênica & Simples & (Zhang et al., 2011) \\
\hline \multicolumn{7}{|l|}{ PEI-PEG } \\
\hline PCL-PEG & $\begin{array}{l}\text { Metanol e } \\
\text { clorofórmio }\end{array}$ & Bioconjugação & siRNA & Entrega gênica & Simples & (Kim \& Yoo, 2013) \\
\hline PET & HFIP & Adsorção física & siRNA/PEI & Entrega gênica & Simples & (Nabzdyk et al., 2014) \\
\hline PLGA & THF, DMF & Camada a camada & pDNA & Entrega gênica & Simples & (Ramalingam et al., 2016) \\
\hline NBR, PEGDM & Clorofórmio & Adsorção física & ssDNA & Sensor & Simples & (Kerr-Phillips et al., 2018) \\
\hline \multirow[t]{2}{*}{ PCL } & HFIP & Bioconjugação & DNA & Engenharia de & Simples & (Malek-Khatabi et al., 2020) \\
\hline & & & DNA/quitosana & tecidos & & \\
\hline
\end{tabular}

1. PLGA ((poli(ácido lático-co-ácido glicólico)), PEI (polietilenimina), PELA (poli(etileno glicol)-poli(D,L-lactídeo)), PLLA (poli(ácido Llático)), PCL (policaprolactona), PEG (polietilenoglicol), PET (politereftalato de etileno), NBR (borracha de acrilonitrilo butadieno), PEGDM (dimetacrilato de polietilenglicol).

2. DCM (diclorometano), HFIP (1,1,1,3,3,3 hexafluoro2-propanol), THF (tetraidrofurano), DMF (N,N-dimetilformamida).

3. pDNA (plasmídeo), siRNA (RNA interferente curto), ssDNA (DNA de fita simples).

Fonte: Os autores (2021).

Os sistemas com nanofibras de PLGA/HAp produzidas por Nie e Wang (2007) tiverem diferentes perfis de liberação de pDNA. As matrizes com complexos de pDNA/quitosana foram capazes de manter a liberação por até 60 dias, sendo a técnica de encapsulação a que resultou em maior tempo e maior eficiência de transfecção em comparação à imobilização na superfície. Em testes in vivo para tratamento de defeito na tíbia de camundongos, as matrizes com pDNA nu em sua superfície 
apresentaram melhores resultados em duas semanas, ao passo que naquelas com oligonucleotídeos encapsulados, após quatro semanas (Nie et al., 2009). No entanto, é necessário haver um equilíbrio entre a eficiência de transfecção e a viabilidade celular. A liberação inicial considerável dessas nanopartículas leva a uma elevada citotoxicidade e menor expressão gênica a longo prazo.

Por outro lado, a expressão transgênica pôde ser controlada variando sua concentração e o número de camadas depositadas na superfície da fibra. Sakai et al. (2009), por exemplo, modificaram a superfície de fibras eletrofiadas de PLLA com a adsorção camada a camada (LbL) de complexos de PEI e DNA presentes em solução. Ramalingam et al. (2016), por sua vez, utilizaram a técnica camada por camada para a formação de nanocamadas de quitosana (polímero catiônico) e alginato (polímero aniônico). Nesse experimento, complexos de pDNA-dendrímeros e pDNA-PEI foram imobilizados nas fibras a partir da interação em uma dispersão.

Polímeros catiônicos como PLLA são vetores promissores para terapia gênica, como alternativa aos vírus por estes possuírem alta citotoxicidade e imunogenicidade, sendo o PEI, sobretudo na forma linear, um dos mais importantes agentes de transferência (Itaka et al., 2004; Kondinskaia et al., 2016). Honoré et al. (2005) não observaram qualquer inibição dos pDNA complexados com derivados de PEI nas proporções consideradas ótimas para transferência gênica.

Diante disso, a estabilidade do complexo DNA-policátion depende fortemente da concentração do polímero e da estrutura química/estado de protonação do polímero catiônico. O PEI forma complexos com maior carga positiva devido à alta afinidade com grupos fosfato. PEI e PEA têm o mesmo nível de protonação, sendo que a diferença está na hidrofobicidade da cadeia principal: o PEI possui grupos amina na cadeia principal enquanto o PVA não possui (Kondinskaia \& Gurtovenko, 2018). Uma outra abordagem é a formação de policátions nas nanofibras antes da funcionalização com oligonucleotídeos. Nabzdyk et al. (2014) realizaram esse processo através da incubação das fibras de PET em solução de etilenodiamina.

A eficiência de incorporação de DNA (w/w, \%) foi analisada por Kim \& Yoo (2010). Uma maior eficiência é explicada quando a razão de cargas entre nitrogênio-fosfato do LPEI imobilizado e do DNA incorporado aumenta, o que pode ser explicada pela elevada densidade de carga positiva na superfície da fibra comparada à densidade de ânions sobre o DNA. Eles concluíram que exposição da úlcera diabética às nanofibras aceleraram a expressão do transgene pela complexação entre o LPEI e o DNA liberados, em resposta às metaloproteinases.

Em outro experimento utilizando a mesma matriz, Kim \& Yoo (2013) utilizaram soluções concentradas de siRNA para aumentar a eficiência de incorporação do material genético sobre a matriz, pois o siRNA apresenta menor densidade de carga aniônica e consequentemente resulta em interações mais fracas quando comparadas ao DNA. Os autores, contudo, observaram que a eficiência de incorporação do siRNA independe daquela razão de cargas N/P, ao qual poder-se-ia atribuir o baixo peso molecular dessa molécula. Os autores concluíram que as nanofibras com razão N/P=32 administradas em úlceras diabéticas in vivo resultaram em recuperação mais rápida quando comparadas às soluções de siRNA. Honoré et al. (2005), por outro lado, apontam que a razão N/P influencia a condensação do DNA e, em consequência, determina a acessibilidade do plasmídeo aos mecanismos de transcrição.

Kerr-Phillips et al. (2018) produziram microfibras de NBR e PEGDM por eletrofiação convencional e as utilizaram em sensores para detecção de linfoma não-Hodgkin. Sua estrutura é similar àquelas produzidas por eletrofiação coaxial; porém, é resultado da polimerização do EDOT e formação de PEDOT interpenetrado nas microfibras. Moléculas de PAA foram ligadas a superfície da fibra e uma sonda covalentemente ligada a ThPhEG:THPhCONH foi sintetizada potenciodinamicamente sobre esse polímero. Os autores justificam a utilização do PAA pela sua hidrofobicidade, o que reduz o contato do substrato com a água, não afetando o desempenho do sensor. 


\subsubsection{Adsorção}

Diferente das estratégias direcionadas à entrega gênica, a adsorção pode ser investigada no âmbito da remoção de ácidos nucleicos de soluções como alternativa para técnicas de biologia molecular (Barbosa et al., 2019). Nesses casos, pode-se explorar a formação de complexos estabilizados por grupos amina protonados do policátion e grupos fosfato do DNA (Kondinskaia et al., 2016). A Tabela 4 apresenta os estudos de adsorção de DNA por fibras produzidas por eletrofiação convencional.

Tabela 4: Adsorção de DNA por fibras eletrofiadas.

\begin{tabular}{|c|c|c|c|c|c|c|}
\hline Polímeros ${ }^{1}$ & Solvente $^{2}$ & Capilar & $q\left(\mathrm{mg}^{-g^{-1}}\right)$ & Isoterma & Cinética & Referência \\
\hline $\begin{array}{l}\text { Acetato de } \\
\text { celulose }\end{array}$ & $\begin{array}{l}\text { DCM e } \\
\text { metanol }\end{array}$ & Simples & 23,51 & Langmuir & - & (Demirci et al., 2014) \\
\hline $\begin{array}{l}\text { Eudragit-E100, } \\
\text { PEO }\end{array}$ & Etanol e água & Simples & 44,31 & $\begin{array}{l}\text { Langmuir e } \\
\text { Freundlich }\end{array}$ & PSO & (Barbosa et al., 2019) \\
\hline
\end{tabular}

1. PEO poli(óxido de etileno).

2. DCM (diclorometano).

Fonte: Os autores (2021).

Demirci et al. (2014) produziram fibras de acetato de celulose (CA) que foram funcionalizadas com crescimento de poli(VBTAC)) mediado por transferência reversível de cadeia por adição-fragmentação (RAFT) na superfície. As fibras catiônicas de poli(VBTAC)-g-CA então produzidas interagiram em meio aquoso com diferentes concentrações de dsDNA marcado com Cy3. Essas fibras apresentaram capacidade máxima de $23,51 \mathrm{mg} \cdot \mathrm{g}^{-1}$ segundo o modelo de Langmuir (1916), que considera a adsorção em monocamada, sobre uma superfície uniforme com sítios finitos para interação. Esse valor é bastante superior ao observado nos ensaios com fibras de acetato de celulose que foi de $2,4 \mathrm{mg} \cdot \mathrm{g}^{-1}$.

Barbosa et al. (2019), por sua vez, desenvolveu nanofibras de Eudragit-E100 e PEO por eletrofiação para adsorção de ssDNA de esperma de salmão. A partir dos ensaios em diferentes concentrações do ácido nucleico, as fibras a apresentaram capacidade máxima de 44,31 mg.g ${ }^{-1}$ segundo o modelo de Langmuir (1916) e a cinética de adsorção seguiu o modelo de pseudo segunda ordem, indicando que o processo é homogêneo.

Assim, as fibras eletrofiadas poderiam integrar estratégias em processos de separação, no esforço para redução no número de etapas de extração e purificação de DNA de interesse visando sobretudo o desenvolvimento de novas abordagens de diagnóstico de doenças com fácil manipulação de material biológico (Habyarimana et al., 2018; Maciel et al., 2018; Tan \& Yiap, 2009). Com o desenvolvimento da engenharia genética, há de se considerar também os riscos de transferência horizontal de genes ou "poluição gênica", sendo oportuno o desenvolvimento de matrizes para captura de DNA recombinante (Baquero, 2004; Panoff \& Chuiton, 2004).

\section{Considerações Finais}

As fibras eletrofiadas podem ser facilmente produzidas e suas características ajustadas segundo um perfil adequado de liberação de polinucleotídeos, tendo como finalidade a manutenção de concentrações de seus tipos moleculares em níveis terapêuticos e por maior tempo. A literatura mostra que o grande desafio é evitar o pico de liberação inicial dessas moléculas, quer variando o componente biodegradável da matriz pela combinação de polímeros hidrofílicos e hidrofóbicos, quer funcionalizando essas fibras com DNA ou RNA na superfície ou em seu interior. A utilização de polímeros como a PEI e PEG 
pode aumentar a disponibilidade desses ácidos nucleicos no microambiente. Para reduzir a degradação do material genético em condições fisiológicas é comum a encapsulação dessas moléculas por eletrofiação coaxial, com o agente bioativo no núcleo. A utilização de fibras eletrofiadas funcionalizadas com material genético se mostra promissor nas terapias de reconstrução tecidual bem como no silenciamento gênico local, por terem características customizáveis que permitem modular a disponibilidade de material genético além de permitir sua integridade. Além disso, o emprego de fibras eletrofiadas complexadas com material representa um excelente protótipo de curativo inteligente, ao permitir boa adesão com o tecido, trocas gasosas e demais parâmetros de interação do curativo com o ferimento, viabilizando com que menor quantidade de antibiótico seja utilizado em tratamento de ferimentos crônicos.

\section{Agradecimentos}

Os autores agradecem o apoio do CNPq, CAPES, FACEPE, FINEP e FAPESB.

\section{Referências}

Achille, C., Sundaresh, S., Chu, B., \& Hadjiargyrou, M. (2012). Cdk2 silencing via a DNA/PCL electrospun scaffold suppresses proliferation and increases death of breast cancer cells. Plos One, 7(12), e52356. https://doi.org/10.1371/journal.pone.0052356

Akbar, Z., Zahoor, T., Huma, N., Jamil, A., Ayesha, H., \& Irudayaraj, J. M. K. (2018). Electrospun probiotics: an alternative for encapsulation. Journal of Biological Regulators and Homeostatic Agents, 32(6), 1551-1556.

Baek, J., Lee, E., Lotz, M. K., \& D’Lima, D. D. (2020). Bioactive proteins delivery through core-shell nanofibers for meniscal tissue regeneration. Nanomedicine: Nanotechnology, Biology, and Medicine, 23, 102090. https://doi.org/10.1016/j.nano.2019.102090

Balogh, A., Drávavölgyi, G., Faragó, K., Farkas, A., Vigh, T., Sóti, P. L., Wagner, I., Madarász, J., Pataki, H., Marosi, G., \& Nagy, Z. K. (2014). Plasticized drug-loaded melt electrospun polymer mats: characterization, thermal degradation, and release kinetics. Journal of Pharmaceutical Sciences, 103(4), 12781287. https://doi.org/10.1002/jps.23904

Balogh, A., Farkas, B., Faragó, K., Farkas, A., Wagner, I., Assche, I., Verreck, G., Nagy, Z. K., \& Marosi, G. (2015). Melt-blown and electrospun drug-loaded polymer fiber mats for dissolution enhancement: A comparative study. Journal of Pharmaceutical Sciences, 104(5), $1767-1776$.

https://doi.org/10.1002/jps.24399

Baquero, F. (2004). From pieces to patterns: Evolutionary engineering in bacterial pathogens. Nature Reviews Microbiology, 2(6), 510-518. https://doi.org/10.1038/nrmicro909

Barbosa, J. D. A. B., de França, C. A., Gouveia, J. J. D. S., Gouveia, G. V., da Costa, M. M., \& de Oliveira, H. P. (2019). Eudragit E100/poly(ethylene oxide) electrospun fibers for DNA removal from aqueous solution. Journal of Applied Polymer Science, 136(19). https://doi.org/10.1002/app.47479

Brown, T. D., Dalton, P. D., \& Hutmacher, D. W. (2011). Direct writing by way of melt electrospinning. Advanced Materials, $23(47), 5651-5657$. https://doi.org/10.1002/adma.201103482

Brown, T. D., Dalton, P. D., \& Hutmacher, D. W. (2016). Melt electrospinning today: an opportune time for an emerging polymer process. Progress in Polymer Science, 56, 116-166. https://doi.org/10.1016/j.progpolymsci.2016.01.001

Cao, H., Jiang, X., Chai, C., \& Chew, S. Y. (2010). RNA interference by nanofiber-based siRNA delivery system. Journal of Controlled Release, 144(2), 203212. https://doi.org/10.1016/j.jconrel.2010.02.003

Chen, H. Y., Cheng, K. C., Hsu, R. J., Hsieh, C. W., Wang, H. T., \& Ting, Y. (2020). Enzymatic degradation of ginkgolic acid by laccase immobilized on novel electrospun nanofiber mat. Journal of the Science of Food and Agriculture, 100(6), 2705-2712. https://doi.org/10.1002/jsfa.10301

Chen, L., Lv, J., Ding, L., Yang, G., Mao, Z., Wang, B., Feng, X., Zapotoczny, S., \& Sui, X. (2020). A shape-stable phase change composite prepared from cellulose nanofiber/polypyrrole/polyethylene glycol for electric-thermal energy conversion and storage. Chemical Engineering Journal, $400,125950$. https://doi.org/10.1016/j.cej.2020.125950

Chen, W., Shen, X., Hu, Y., Xu, K., Ran, Q., Yu, Y., Dai, L., Yuan, Z., Huang, L., Shen, T., \& Cai, K. (2017). Surface functionalization of titanium implants with chitosan-catechol conjugate for suppression of ROS-induced cells damage and improvement of osteogenesis. Biomaterials, $114,82-96$. https://doi.org/10.1016/j.biomaterials.2016.10.055

Cheng, J., Jun, Y., Qin, J., \& Lee, S. H. (2017). Electrospinning versus microfluidic spinning of functional fibers for biomedical applications. Biomaterials, 114, 121-143. https://doi.org/10.1016/j.biomaterials.2016.10.040

Chew, S. Y., Wen, Y., Dzenis, Y., \& Leong, K. W. (2006). The role of electrospinning in the emerging field of nanomedicine. Current Pharmaceutical Design, 12(36), 4751-4770.

Chou, S. F., Carson, D., \& Woodrow, K. A. (2015, December). Current strategies for sustaining drug release from electrospun nanofibers. Journal of Controlled Release, 220, 584-591. https://doi.org/10.1016/j.jconrel.2015.09.008 
Chronakis, I. S. (2015). Micro- and nano-fibers by electrospinning technology: processing, properties, and applications. In Micromanufacturing Engineering and Technology: Second Edition (pp. 513-548). Elsevier Inc. https://doi.org/10.1016/B978-0-323-31149-6.00022-0

Demirci, S., Celebioglu, A., \& Uyar, T. (2014). Surface modification of electrospun cellulose acetate nanofibers via RAFT polymerization for DNA adsorption. Carbohydrate Polymers, 113, 200-207. https://doi.org/10.1016/j.carbpol.2014.06.086

Deshawar, D., \& Chokshi, P. (2018). Analysis of axisymmetric instability in polymer melt electrospinning jet. Journal of Non-Newtonian Fluid Mechanics, 255, 1-12. https://doi.org/10.1016/j.jnnfm.2018.03.003

Deshawar, D., Gupta, K., \& Chokshi, P. (2020). Electrospinning of polymer solutions: an analysis of instability in a thinning jet with solvent evaporation. Polymer, 202, 122656. https://doi.org/10.1016/j.polymer.2020.122656

Distler, O., Neidhart, M., Gay, R. E., \& Gay, S. (2002). The molecular control of angiogenesis. International Reviews of Immunology, 21 (1), 33-49. https://doi.org/10.1080/08830180210415

Divvela, M. J., Shepherd, L. M., Frey, M. W., \& Joo, Y. L. (2018). Discretized modeling of motionless printing based on retarded bending motion and deposition control of electrically driven jet. 3D Printing and Additive Manufacturing, 5(3), 248-256. https://doi.org/10.1089/3dp.2017.0134

Doshi, J., \& Reneker, D. H. (1995). Electrospinning process and applications of electrospun fibers. Journal of Electrostatics, 35(2-3), 151-160. https://doi.org/10.1016/0304-3886(95)00041-8

Dvir, T., Timko, B. P., Kohane, D. S., \& Langer, R. (2011). Nanotechnological strategies for engineering complex tissues. Nature Nanotechnology, 6(1), 1322. https://doi.org/10.1038/nnano.2010.246

El-Basaty, A. B., Moustafa, E., Fouda, A. N., \& El-Moneim, A. A. (2020). 3D hierarchical graphene/CNT with interfacial polymerized polyaniline nanofibers. Spectrochimica Acta - Part A: Molecular and Biomolecular Spectroscopy, 226, 117629. https://doi.org/10.1016/j.saa.2019.117629

Fang, X., \& Reneker, D. H. (1997). DNA fibers by electrospinning. Journal of Macromolecular Science - Physics, 36(2), 169-173. https://doi.org/10.1080/00222349708220422

Gañán-Calvo, A. M. (1997). On the theory of electrohydrodynamically driven capillary jets. Journal of Fluid Mechanics, 335, $165-188$. https://doi.org/10.1017/S0022112096004466

Gelain, F., Bottai, D., Vescovi, A., \& Zhang, S. (2006). Designer self-assembling peptide nanofiber scaffolds for adult mouse neural stem cell 3-dimensional cultures. PLoS ONE , 1(1), e119. https://doi.org/10.1371/journal.pone.0000119

Greiner, A., \& Wendorff, J. H. (2007). Electrospinning: a fascinating method for the preparation of ultrathin fibers. Angewandte Chemie - International Edition, 46(30), 5670-5703. https://doi.org/10.1002/anie.200604646

Habyarimana, T., Attaleb, M., Mazarati, J. B., Bakri, Y., \& Mzibri, M. (2018). Detection of human papillomavirus DNA in tumors from Rwandese breast cancer patients. In Breast Cancer (Vol. 25, Issue 2, pp. 127-133). Springer Tokyo. https://doi.org/10.1007/s12282-018-0831-2

Han, T., Reneker, D. H., \& Yarin, A. L. (2007). Buckling of jets in electrospinning. Polymer, 48(20), 6064-6076. https://doi.org/10.1016/j.polymer.2007.08.002

He, J., LI, H., Mchugh, A. D., Wang, Q., Li, H., Rasaily, R. G., \& Sarker, K. K. (2012). Seed zone properties and crop performance as affected by three no-till seeders for permanent raised beds in arid northwest China. Journal of Integrative Agriculture, 11(10), 1654-1664. https://doi.org/10.1016/S20953119(12)60168-3

He, S., Xia, T., Wang, H., Wei, L., Luo, X., \& Li, X. (2012). Multiple release of polyplexes of plasmids VEGF and bFGF from electrospun fibrous scaffolds towards regeneration of mature blood vessels. Acta Biomaterialia, 8(7), 2659-2669. https://doi.org/10.1016/j.actbio.2012.03.044

Honoré, I., Grosse, S., Frison, N., Favatier, F., Monsigny, M., \& Fajac, I. (2005). Transcription of plasmid DNA: Influence of plasmid DNA/polyethylenimine complex formation. Journal of Controlled Release, 107(3), 537-546. https://doi.org/10.1016/j.jconrel.2005.06.018

Hou, J., Yang, J., Zheng, X., Wang, M., Liu, Y., \& Yu, D. G. (2020). A nanofiber-based drug depot with high drug loading for sustained release. International Journal of Pharmaceutics, 583, 119397. https://doi.org/10.1016/j.ijpharm.2020.119397

Huan, S., Liu, G., Han, G., Cheng, W., Fu, Z., Wu, Q., \& Wang, Q. (2015). Effect of experimental parameters on morphological, mechanical and hydrophobic properties of electrospun polystyrene fibers. Materials, 8(5), 2718-2734. https://doi.org/10.3390/ma8052718

Huang, Y., Bu, N., Duan, Y., Pan, Y., Liu, H., Yin, Z., \& Xiong, Y. (2013). Electrohydrodynamic direct-writing. Nanoscale, 5(24), $12007-12017$. https://doi.org/10.1039/c3nr04329k

Huang, Y., Duan, Y., Ding, Y., Bu, N., Pan, Y., Lu, N., \& Yin, Z. (2014). Versatile, kinetically controlled, high precision electrohydrodynamic writing of micro/nanofibers. Scientific Reports, 4(1), 1-9. https://doi.org/10.1038/srep05949

Hui, N., Sun, X., Niu, S., \& Luo, X. (2017). PEGylated polyaniline nanofibers: antifouling and conducting biomaterial for electrochemical DNA sensing. ACS Applied Materials and Interfaces, 9(3), 2914-2923. https://doi.org/10.1021/acsami.6b11682

Itaka, K., Harada, A., Yamasaki, Y., Nakamura, K., Kawaguchi, H., \& Kataoka, K. (2004). In situ single cell observation by fluorescence resonance energy transfer reveals fast intra-cytoplasmic delivery and easy release of plasmid DNA complexed with linear polyethylenimine. Journal of Gene Medicine, 6(1), 76-84. https://doi.org/10.1002/jgm.470

Jacobs, V., Anandjiwala, R. D., \& Maaza, M. (2010). The influence of electrospinning parameters on the structural morphology and diameter of electrospun 
nanofibers. Journal of Applied Polymer Science, 115(5), 3130-3136. https://doi.org/10.1002/app.31396

Jao, D., \& Beachley, V. Z. (2019). Continuous dual-track fabrication of polymer micro-/nanofibers based on direct drawing. ACS Macro Letters, 588-595. https://doi.org/10.1021/acsmacrolett.9b00167

Joshi, V., Srivastava, C. M., Gupta, A. P., \& Vats, M. (2020). Electrospun nano-architectures for tissue engineering and regenerative medicine (pp. 213-248). Springer, Cham. https://doi.org/10.1007/978-3-030-29207-2_7

Kara, Y., He, H., \& Molnár, K. (2020). Shear-aided high-throughput electrospinning: a needleless method with enhanced jet formation. Journal of Applied Polymer Science, 137(37), 49104. https://doi.org/10.1002/app.49104

Kasyanenko, N., Afanasieva, D., Dribinsky, B., Mukhin, D., Nazarova, O., \& Panarin, E. (2007). DNA interaction with synthetic polymers in solution. Structural Chemistry, 18(4), 519-525. https://doi.org/10.1007/s11224-007-9162-1

Ke, F., Luu, Y. K., Hadjiargyrou, M., \& Liang, D. (2010). Characterizing DNA condensation and conformational changes in organic solvents. PLoS ONE, 5(10), e13308. https://doi.org/10.1371/journal.pone.0013308

Kerr-Phillips, T. E., Aydemir, N., Chan, E. W. C., Barker, D., Malmström, J., Plesse, C., \& Travas-Sejdic, J. (2018). Conducting electrospun fibres with polyanionic grafts as highly selective, label-free, electrochemical biosensor with a low detection limit for non-Hodgkin lymphoma gene. Biosensors and Bioelectronics, 100, 549-555. https://doi.org/10.1016/j.bios.2017.09.042

Kim, H. S., \& Yoo, H. S. (2010). MMPs-responsive release of DNA from electrospun nanofibrous matrix for local gene therapy: In vitro and in vivo evaluation. Journal of Controlled Release, 145(3), 264-271. https://doi.org/10.1016/j.jconrel.2010.03.006

Kim, H. S., \& Yoo, H. S. (2013). Matrix metalloproteinase-inspired suicidal treatments of diabetic ulcers with siRNA-decorated nanofibrous meshes. Gene Therapy, 20(4), 378-385. https://doi.org/10.1038/gt.2012.49

Kim, J. F., Kim, J. H., Lee, Y. M., \& Drioli, E. (2016). Thermally induced phase separation and electrospinning methods for emerging membrane applications: A review. AIChE Journal, 62(2), 461-490. https://doi.org/10.1002/aic.15076

Kondinskaia, D. A., \& Gurtovenko, A. A. (2018). Supramolecular complexes of DNA with cationic polymers: The effect of polymer concentration. Polymer, 142, 277-284. https://doi.org/10.1016/j.polymer.2018.03.048

Kondinskaia, D. A., Kostritskii, A. Y., Nesterenko, A. M., Antipina, A. Y., \& Gurtovenko, A. A. (2016). Atomic-scale molecular dynamics simulations of DNA-polycation complexes: two distinct binding patterns. Journal of Physical Chemistry B, 120(27), 6546-6554. https://doi.org/10.1021/acs.jpcb.6b03779

Košt'áková, E., Seps, M., Pokorny, P., \& Lukas, D. (2014). Study of polycaprolactone wet electrospinning process. Express Polymer Letters, 8(8), 554-564. Langmuir, I. (1916). The constitution and fundamental properties of solids and liquids. Journal of the American Chemical Society, $38(11), 2221-2295$. https://doi.org/10.1021/ja02268a002

Li, D., \& Xia, Y. (2004, July). Electrospinning of nanofibers: Reinventing the wheel? Advanced Materials, 16(14), 1151-1170. https://doi.org/10.1002/adma.200400719

Li, W. J., Shanti, R. M., \& Tuan, R. S. (2007). Electrospinning technology for nanofibrous scaffolds in tissue engineering. Nanotechnologies for the Life Sciences, 9, 135-187.

Li, W. J., \& Tuan, R. S. (2009). Fabrication and application of nanofibrous scaffolds in tissue engineering. In Current protocols in cell biology. https://doi.org/10.1002/0471143030.cb2502s42

Li, X., Zheng, Y., Mu, X., Xin, B., \& Lin, L. (2020). The effects of electric field on jet behavior and fiber properties in melt electrospinning. Fibers and Polymers, 21(5), 984-992. https://doi.org/10.1007/s12221-020-9849-0

Liang, D., Luu, Y. K., Kim, K., Hsiao, B. S., Hadjiargyrou, M., \& Chu, B. (2005). In vitro non-viral gene delivery with nanofibrous scaffolds. Nucleic Acids Research, 33(19), 1-10. https://doi.org/10.1093/nar/gni171

Liao, I. C., Chen, S., Liu, J. B., \& Leong, K. W. (2009). Sustained viral gene delivery through core-shell fibers. Journal of Controlled Release, $139(1)$, 48-55. https://doi.org/10.1016/j.jconrel.2009.06.007

Liu, S., \& Reneker, D. H. (2019). Droplet-jet shape parameters predict electrospun polymer nanofiber diameter. Polymer, 168, 155-158. https://doi.org/10.1016/j.polymer.2019.01.082

Liu, Y., Chen, J., Misoska, V., \& Wallace, G. G. (2007). Preparation of novel ultrafine fibers based on DNA and poly(ethylene oxide) by electrospinning from aqueous solutions. Reactive and Functional Polymers, 67(5), 461-467. https://doi.org/10.1016/j.reactfunctpolym.2007.02.008

Liu, Z., Lu, Y., Confer, M. P., Cui, H., Li, J., Li, Y., Wang, Y., Street, S. C., Wujcik, E. K., \& Wang, R. (2020). Thermally stable RuOx -CeO2 nanofiber catalysts for low-temperature CO oxidation . ACS Applied Nano Materials, 3(8), 8403-8413. https://doi.org/10.1021/acsanm.0c01815

Liu, Z., Ramakrishna, S., \& Liu, X. (2020). Electrospinning and emerging healthcare and medicine possibilities. APL Bioengineering, 4 (3), 030901. https://doi.org/10.1063/5.0012309

Luo, C. J., Stride, E., \& Edirisinghe, M. (2012). Mapping the influence of solubility and dielectric constant on electrospinning polycaprolactone solutions. Macromolecules, 45(11), 4669-4680. https://doi.org/10.1021/ma300656u

Luu, Y. K., Kim, K., Hsiao, B. S., Chu, B., \& Hadjiargyrou, M. (2003). Development of a nanostructured DNA delivery scaffold via electrospinning of PLGA and PLA-PEG block copolymers. Journal of Controlled Release, 89(2), 341-353. https://doi.org/10.1016/S0168-3659(03)00097-X 
Maciel, B. G., Silva, R. J., Chávez-Guajardo, A. E., Medina-Llamas, J. C., Alcaraz-Espinoza, J. J., \& de Melo, C. P. (2018). Magnetic extraction and purification of DNA from whole human blood using a $\gamma$-Fe2O3@Chitosan@ Polyaniline hybrid nanocomposite. Carbohydrate Polymers, 197, 100-108. https://doi.org/10.1016/j.carbpol.2018.05.034

Malek-Khatabi, A., Javar, H. A., Dashtimoghadam, E., Ansari, S., Hasani-Sadrabadi, M. M., \& Moshaverinia, A. (2020). In situ bone tissue engineering using gene delivery nanocomplexes. Acta Biomaterialia, 108, 326-336. https://doi.org/10.1016/j.actbio.2020.03.008

Monaghan, M., \& Pandit, A. (2011, April). RNA interference therapy via functionalized scaffolds. Advanced Drug Delivery Reviews, 63(4), $197-208$. https://doi.org/10.1016/j.addr.2011.01.006

Montinaro, M., Fasano, V., Moffa, M., Camposeo, A., Persano, L., Lauricella, M., Succi, S., \& Pisignano, D. (2015). Sub-ms dynamics of the instability onset of electrospinning. Soft Matter, 11(17), 3424-3431. https://doi.org/10.1039/c4sm02708f

Nabzdyk, C. S., Chun, M. C., Oliver-Allen, H. S., Pathan, S. G., Phaneuf, M. D., You, J. O., Pradhan-Nabzdyk, L. K., \& LoGerfo, F. W. (2014). Gene silencing in human aortic smooth muscle cells induced by PEI-siRNA complexes released from dip-coated electrospun poly(ethylene terephthalate) grafts. Biomaterials, 35(9), 3071-3079. https://doi.org/10.1016/j.biomaterials.2013.12.026

Nagiah, N., Johnson, R., Anderson, R., Elliott, W., \& Tan, W. (2015). Highly compliant vascular grafts with gelatin-sheathed coaxially structured nanofibers. Langmuir, 31(47), 12993-13002. https://doi.org/10.1021/acs.langmuir.5b03177

Nie, H., Ho, M. L., Wang, C. K., Wang, C. H., \& Fu, Y. C. (2009). BMP-2 plasmid loaded PLGA/HAp composite scaffolds for treatment of bone defects in nude mice. Biomaterials, 30(5), 892-901. https://doi.org/10.1016/j.biomaterials.2008.10.029

Nie, H., \& Wang, C. H. (2007). Fabrication and characterization of PLGA/HAp composite scaffolds for delivery of BMP-2 plasmid DNA. Journal of Controlled Release, 120(1-2), 111-121. https://doi.org/10.1016/j.jconrel.2007.03.018

Okonkwo, U. A., \& DiPietro, L. A. (2017). Diabetes and Wound Angiogenesis. International Journal of Molecular Sciences, $18(7), 1419$. https://doi.org/10.3390/ijms18071419

Panoff, J. M., \& Chuiton, C. (2004). Horizontal gene transfer: A universal phenomenon. Human and Ecological Risk Assessment, 10(5), 939-943. https://doi.org/10.1080/10807030490513928

Perez, M. A., Swan, M. D., \& Louks, J. W. (2000). Microfibers and method of making (Patent No. 6110588). Google Patents.

Persano, L., Camposeo, A., Tekmen, C., \& Pisignano, D. (2013, May). Industrial upscaling of electrospinning and applications of polymer nanofibers: A review. Macromolecular Materials and Engineering, 298(5), 504-520. https://doi.org/10.1002/mame.201200290

Phelps, E. A., \& Garcia, A. J. (2009). Update on therapeutic vascularization strategies. Regenerative Medicine, 4(1), 65-80. https://doi.org/10.2217/17460751.4.1.65

Pike, R. D. (1999). Superfine microfiber nonwoven web (Patent No. 5935883). Google Patents.

Pouton, C. W., \& Seymour, L. W. (2001). Key issues in non-viral gene delivery. Advanced Drug Delivery Reviews, 46(1-3), 187-203. https://doi.org/10.1016/S0169-409X(00)00133-2

Raemdonck, K., Vandenbroucke, R. E., Demeester, J., Sanders, N. N., \& Smedt, S. C. (2008). Maintaining the silence: reflections on long-term RNAi. In Drug Discovery Today (Vol. 13, Issues 21-22, pp. 917-931). Elsevier Current Trends. https://doi.org/10.1016/j.drudis.2008.06.008

Ramalingam, K., Castro, R., Pires, P., Shi, X., Rodrigues, J., Xiao, S., \& Tomás. (2016). Gene delivery using dendrimer/pDNA complexes immobilized in electrospun fibers using the Layer-by-Layer technique. RSC Advances, 6(99), 97116-97128. https://doi.org/10.1039/c6ra22444j

Rieux, A., Ucakar, B., Mupendwa, B. P. K., Colau, D., Feron, O., Carmeliet, P., \& Préat, V. (2011). 3D systems delivering VEGF to promote angiogenesis for tissue engineering. Journal of Controlled Release, 150(3), 272-278. https://doi.org/10.1016/j.jconrel.2010.11.028

Roether, J., Bertels, S., Oelschlaeger, C., Bastmeyer, M., \& Willenbacher, N. (2018). Microstructure, local viscoelasticity and cell culture suitability of 3D hybrid HA/collagen scaffolds. Plos One, 13(12), e0207397. https://doi.org/10.1371/journal.pone.0207397

Rujitanaroj, P. O., Wang, Y. C., Wang, J., \& Chew, S. Y. (2011). Nanofiber-mediated controlled release of siRNA complexes for long term gene-silencing applications. Biomaterials, 32(25), 5915-5923. https://doi.org/10.1016/J.BIOMATERIALS.2011.04.065

Rujitanaroj, P., Wang, Y. C., Wang, J., \& Chew, S. Y. (2011). Nanofiber-mediated controlled release of siRNA complexes for long term gene-silencing applications. Biomaterials, 32(25), 5915-5923. https://doi.org/10.1016/j.biomaterials.2011.04.065

Sakai, S., Yamada, Y., Yamaguchi, T., Ciach, T., \& Kawakami, K. (2009). Surface immobilization of poly(ethyleneimine) and plasmid DNA on electrospun poly(L-lactic acid) fibrous mats using a layer-by-layer approach for gene delivery. Journal of Biomedical Materials Research Part A, 88A(2), $281-287$. https://doi.org/10.1002/jbm.a.31870

Sandri, G., Rossi, S., Bonferoni, M. C., Caramella, C., \& Ferrari, F. (2020). Electrospinning technologies in wound dressing applications. In Therapeutic Dressings and Wound Healing Applications (pp. 315-336). Wiley. https://doi.org/10.1002/9781119433316.ch14

Saraf, A., Baggett, L. S., Raphael, R. M., Kasper, F. K., \& Mikos, A. G. (2010). Regulated non-viral gene delivery from coaxial electrospun fiber mesh scaffolds. Journal of Controlled Release, 143(1), 95-103. https://doi.org/10.1016/j.jconrel.2009.12.009

Sell, S. A., Wolfe, P. S., Garg, K., McCool, J. M., Rodriguez, I. A., \& Bowlin, G. L. (2010). The Use of Natural Polymers in Tissue Engineering: A Focus on Electrospun Extracellular Matrix Analogues. Polymers, 2(4), 522-553. https://doi.org/10.3390/polym2040522 
Shea, L. D., Smiley, E., Bonadio, J., \& Mooney, D. J. (1999). DNA delivery from polymer matrices for tissue engineering. Nature Biotechnology, 17(6), 551554. https://doi.org/10.1038/9853

Shepherd, L. M., Frey, M. W., \& Joo, Y. L. (2017). Immersion electrospinning as a new method to direct fiber deposition. Macromolecular Materials and Engineering, 302(10), 1700148. https://doi.org/10.1002/mame.201700148

Smedt, S. C., Demeester, J., \& Hennink, W. E. (2000). Cationic polymer based gene delivery systems. Pharmaceutical Research, 17(2), 113-126. https://doi.org/10.1023/A:1007548826495

Song, J., Li, Z., \& Wu, H. (2020). Blowspinning: a new choice for nanofibers. ACS Applied Materials \& Interfaces, 12(30), 33447-33464. https://doi.org/10.1021/acsami.0c05740

Sun, F., Chen, L., Ding, X., Xu, L., Zhou, X., Wei, P., Liang, J. F., \& Luo, S. Z. (2017). High-Resolution Insights into the Stepwise Self-Assembly of Nanofiber from Bioactive Peptides. Journal of Physical Chemistry B, 121(31), 7421-7430. https://doi.org/10.1021/acs.jpcb.7b03626

Takahashi, T., Taniguchi, M., \& Kawai, T. (2005). Fabrication of DNA nanofibers on a planar surface by electrospinning. Japanese Journal of Applied Physics, Part 2: Letters, 44(24-27), L860. https://doi.org/10.1143/JJAP.44.L860

Tan, S. C., \& Yiap, B. C. (2009). DNA, RNA, and protein extraction: the past and the present. Journal of Biomedicine and Biotechnology, 2009. https://doi.org/10.1155/2009/574398

Tao, S. L., \& Desai, T. A. (2007). Aligned arrays of biodegradable poly( $\varepsilon$-caprolactone) nanowires and nanofibers by template synthesis. Nano Letters, 7(6), 1463-1468. https://doi.org/10.1021/n10700346

Taylor, G. I. (1969). Electrically driven jets. Proceedings of the Royal Society of London. A. Mathematical and Physical Sciences, 313(1515), 453-475. https://doi.org/10.1098/rspa.1969.0205

Thakkar, S., \& Misra, M. (2017). Electrospun polymeric nanofibers: new horizons in drug delivery. European Journal of Pharmaceutical Sciences, 107, 148167. https://doi.org/10.1016/j.ejps.2017.07.001

Villarreal-Gómez, L. J., Cornejo-Bravo, J. M., Vera-Graziano, R., \& Grande, D. (2016). Electrospinning as a powerful technique for biomedical applications: A critically selected survey. Journal of Biomaterials Science, Polymer Edition, 27(2), 157-176. https://doi.org/10.1080/09205063.2015.1116885

Wang, X., \& Nakane, K. (2020). Preparation of polymeric nanofibers via immersion electrospinning. European Polymer Journal, $134,109837$. https://doi.org/10.1016/j.eurpolymj.2020.109837

Wu, R. A., Lin, C. W., \& Tseng, W. J. (2017). Preparation of electrospun Cu-doped $\alpha$-Fe2O3 semiconductor nanofibers for NO2 gas sensor. Ceramics International, 43, S535-S540. https://doi.org/10.1016/j.ceramint.2017.05.285

Xie, Q., Jia, L. N., Xu, H. Y., Hu, X. G., Wang, W., \& Jia, J. (2016). Fabrication of core-shell PEI/pBMP2-PLGA electrospun Scaffold for gene delivery to periodontal ligament stem cells. Stem Cells International, 2016. https://doi.org/10.1155/2016/5385137

Xue, J., Wu, T., Dai, Y., \& Xia, Y. (2019). Electrospinning and electrospun nanofibers: methods, materials, and applications. In Chemical Reviews (Vol. 119, Issue 8, pp. 5298-5415). American Chemical Society. https://doi.org/10.1021/acs.chemrev.8b00593

Xue, J., Xie, J., Liu, W., \& Xia, Y. (2017). Electrospun nanofibers: new concepts, materials, and applications. Accounts of Chemical Research, 50(8), 19761987. https://doi.org/10.1021/acs.accounts.7b00218

Yang, P., Yang, L., Gao, Q., Luo, Q., Zhao, X., Mai, X., Fu, Q., Dong, M., Wang, J., Hao, Y., Yang, R., Lai, X., Wu, S., Shao, Q., Ding, T., Lin, J., \& Guo, Z. (2019). Anchoring carbon nanotubes and post-hydroxylation treatment enhanced Ni nanofiber catalysts towards efficient hydrous hydrazine decomposition for effective hydrogen generation. Chemical Communications, 55(61), 9011-9014. https://doi.org/10.1039/c9cc04559g

Yang, Y., Li, X., Cheng, L., He, S., Zou, J., Chen, F., \& Zhang, Z. (2011). Core-sheath structured fibers with pDNA polyplex loadings for the optimal release profile and transfection efficiency as potential tissue engineering scaffolds. Acta Biomaterialia, 7(6), 2533-2543. https://doi.org/10.1016/j.actbio.2011.02.031

Yang, Y., Xia, T., Chen, F., Wei, W., Liu, C., He, S., \& Li, X. (2012). Electrospun fibers with plasmid bFGF polyplex loadings promote skin wound healing in diabetic rats. Molecular Pharmaceutics, 9(1), 48-58. https://doi.org/10.1021/mp200246b

Yar, A., Karabiber, A., Ozen, A., Ozel, F., \& Coskun, S. (2020). Flexible nanofiber based triboelectric nanogenerators with high power conversion. Renewable Energy, 162, 1428-1437. https://doi.org/10.1016/j.renene.2020.08.030

Yarin, A. L., Koombhongse, S., \& Reneker, D. H. (2001). Bending instability in electrospinning of nanofibers. Journal of Applied Physics, 89(5), 3018-3026. https://doi.org/10.1063/1.1333035

Yin, X., Yu, J., \& Ding, B. (2020). Electrospun Fibers for Filtration. In Handbook of Fibrous Materials (pp. 175-206). Wiley. https://doi.org/10.1002/9783527342587.ch7

Yu, J. H., Fridrikh, S. V, \& Rutledge, G. C. (2006). The role of elasticity in the formation of electrospun fibers. Polymer, 47(13), 4789-4797. https://doi.org/10.1016/j.polymer.2006.04.050

Zamani, M., Prabhakaran, M. P., \& Ramakrishna, S. (2013). Advances in drug delivery via electrospun and electrosprayed nanomaterials. International Journal of Nanomedicine, 8(1), 3017. https://doi.org/10.2147/IJN.S43575

Zandi, N., Lotfi, R., Tamjid, E., Shokrgozar, M. A., \& Simchi, A. (2020). Core-sheath gelatin based electrospun nanofibers for dual delivery release of biomolecules and therapeutics. Materials Science and Engineering C, 108, 110432. https://doi.org/10.1016/j.msec.2019.110432 
Research, Society and Development, v. 10, n. 5, e19210514953, 2021

(CC BY 4.0) | ISSN 2525-3409 | DOI: http://dx.doi.org/10.33448/rsd-v10i5.14953

Zhang, J., Duan, Y., Wei, D., Wang, L., Wang, H., Gu, Z., \& Kong, D. (2011). Co-electrospun fibrous scaffold-adsorbed DNA for substrate-mediated gene delivery. Journal of Biomedical Materials Research Part A, 96A(1), 212-220. https://doi.org/10.1002/jbm.a.32962

Zheng, X., Bian, T., Zhang, Y., Zhang, Y., \& Li, Z. (2020). Construction of ion-imprinted nanofiber chitosan films using low-temperature thermal phase separation for selective and efficiency adsorption of Gd(III). Cellulose, 27(1), 455-467. https://doi.org/10.1007/s10570-019-02804-3

Zhou, H., Green, T. B., \& Joo, Y. L. (2006). The thermal effects on electrospinning of polylactic acid melts. Polymer, 47(21), 7497-7505. https://doi.org/10.1016/j.polymer.2006.08.042

Zhu, F., Xin, Q., Feng, Q., Zhou, Y., \& Liu, R. (2015). Novel poly(vinylidene fluoride)/thermoplastic polyester elastomer composite membrane prepared by the electrospinning of nanofibers onto a dense membrane substrate for protective textiles. Journal of Applied Polymer Science, 132(26). https://doi.org/10.1002/app.42170

Ziabari, M., Mottaghitalab, V., \& Haghi, A. K. (2010). A new approach for optimization of electrospun nanofiber formation process. Korean Journal of Chemical Engineering, 27(1), 340-354. https://doi.org/10.1007/s11814-009-0309-1 